\title{
Cr(VI) Removal from Aqueous Solution by Chitosan/Carboxylmethyl Cellulose/Silica Hybrid Membrane
}

\author{
Xuemei He, Huidong Xu, Hui Li \\ College of Textiles and Clothing, Yancheng Institute of Technology, Jiangsu, China \\ Email: hexuemei@ycit.cn
}

Received 6 August 2015; accepted 16 October 2015; published 23 October 2015

\begin{abstract}
In the present study, chitosan/carboxymethyl cellulose/silica hybrid membrane (CS/CMC/Silica) was prepared by using chitosan and carboxymethyl cellulose in the presence of 3-glycidoxypropyltrimethoxysilane (GPTMS) as the crosslinking agent and used to remove $\operatorname{Cr}$ (VI) iron in effluent. The structure of CS/CMC/Silica hybrid membrane was characterized by FT-IR spectroscopy and scanning electron microscopy (SEM). The influence of $\mathrm{Cr}(\mathrm{VI})$ concentration, solution temperature, and $\mathrm{pH}$, adsorption time on adsorption performance of hybrid membrane was investigated. Adsorption capacity increased with the increase of $\operatorname{Cr}(\mathrm{VI})$ concentration and absorbing time, and decreased with the increase of sorbent dosage and temperature. The adsorption equilibrium of $\operatorname{Cr}(\mathrm{VI})$ ion was attained within $60 \mathrm{~min}$ of contact. The pseudo-second-order model fitted the kinetic data well.
\end{abstract}

\section{Keywords}

Chitosan, Carboxymethyl Cellulose, Silica, Hybrid, Adsorption

\section{Introduction}

Chitosan (CS), N-deacetylated form of chitin, is the second abundant renewable biopolymer, next to cellulose [1] [2]. Due to its many unique properties such as good coagulating properties, excellent forming film characteristics, nontoxic, environment-friendly, low-cost and high-efficiency, high contents of amino and hydroxyl functional groups in the chains, recently, it has attracted great attention as a new biosorbent for the significant adsorption potential for the removal of heavy metal ions from textile effluents [3] [4]. However, chitosan membrane is highly swollen in water, which may change its physical structures. On the other hand, the low mechanical strength and poor acid resistance of chitosan membrane are also to be overcome. Blending chitosan with effective compatible polymers, such as carboxymethyl cellulose (CMC), acrylonitrile butadiene styrene and polyvinyl alcohol, etc, is an effective way to strengthen its structure [5]. Owing to its opposite electric charge, CMC can strongly react with CS and acts as an ionic cross-linking agent at the appropriate pH9 [6]-[8]. The composite of CMC/CS has been investigated by some researchers for possible medical applications because of its excellent biocompatibility, biodegradability and hydrophilic [8]-[10]. Some literatures also reported the fabrication of 
porous CMC/CS membranes and application for pervaporation (PV) dehydration and adsorption metal ion [11] [12].

In this work, chitosan and carboxymethyl cellulose were provided as the substrate, using 3-glycidoxypropyltrimethoxysilane (GPTMS) as crosslinking agent. Chitosan/carboxymethyl cellulose/silica (CS/CMC/silica) hybrid membranes were prepared and used to remove $\mathrm{Cr}(\mathrm{VI})$ ions in effluent. The hybrid membranes were characterized by FTIR, SEM. Batch adsorption experiments were carried out to investigate the effects of different conditions, such as the adsorbent dosage, $\mathrm{Cr}(\mathrm{VI})$ ions concentration, adsorption temperature, and solution $\mathrm{pH}$ and contact time, on the adsorption capacity of hybrid membrane for $\mathrm{Cr}(\mathrm{VI})$ ions. The adsorption behavior of the hybrid membranes were analyzed by the pseudo-first-order kinetic model and pseudo-second-order kinetic model.

\section{Experimental}

\subsection{Materials and Characteration}

Chitosan (CS, degree of deacetylation 96.31\%, MW $=7.9 \times 10^{5} \mathrm{Da}$ ) was purchased from Zhejiang Jinke Biotech Co. Ltd. (Zhejiang, China). Carboxymethyl cellulose sodium salt (CMC, M.W. = 800), $\mathrm{K}_{2} \mathrm{Cr}_{2} \mathrm{O}_{7}$ (analytical pure) were purchased from Guoyao Chemical Co. Ltd. (Shanghai, China). 3-Glycidoxypropyltrimethoxysilane (GPTMS) was supplied by Yancheng Renbo Chemical Company (Yancheng, China).

FTIR spectra of the hybrid membrane were recorded using NEXUS-670 (Nicolet, USA) over the range 500 $4000 \mathrm{~cm}^{-1}$. The samples were ground to a very fine powder and mixed with a highly dried KBr powder (200 $\mathrm{mg}$ ), then pressed to transparent tablet. SEM images of the hybrid membrane were taken using a scanning electron microscope FEI Quanta 200 scanning Electron Microscope (USA). The samples were sputtered with gold, and operated at $15 \mathrm{kV}$.

\subsection{Membrane Preparation}

To obtain CS/CMC/silica hybrid membranes, chitosan solution 2\% (w/v) and CMC aqueous solutions 2\% (w/v) were first prepared by dissolving chitosan and CMC in acetic acid $1 \%(\mathrm{v} / \mathrm{v})$ and distilled water, respectively. Then, chitosan solution $2 \%$ was added into CMC solution $2 \%$ until $\mathrm{V}_{\mathrm{CMC}}: \mathrm{V}_{\mathrm{CS}}=1: 1$ with stirring. $1 \%(\mathrm{v} / \mathrm{v})$ GPTMS were drop-wise added into the CS and CMC mixtures, the mixed solutions were adjusted to $\mathrm{pH} 1-2$ using $\mathrm{HCl}$ solution and stirred for $4 \mathrm{~h}$ until an obviously pale yellow viscous liquid occurred. The obtained pale yellow viscous liquid was cast into a clean smooth slide to form membrane in an oven $\left(50^{\circ} \mathrm{C}\right)$ for $24 \mathrm{~h}$. The membrane were neutralized in $\mathrm{NaOH}$ solution $(0.1 \mathrm{M})$ for about $10 \mathrm{~min}$, washed thoroughly with distilled water, and dried again. Finally, CS/CMC/silica hybrid membranes were obtained and named as CSMH.

\subsection{Adsorption Experiments}

Batch experiments were conducted by placing hybrid membranes in $250 \mathrm{~mL}$ bottle containing $\mathrm{Cr}(\mathrm{VI})$ ions. The effect of temperature $\left(30^{\circ} \mathrm{C}-70^{\circ} \mathrm{C}\right)$ on the adsorption was evaluated at $\mathrm{pH}$ 7.0. The effect of the initial concentration of $\mathrm{Cr}(\mathrm{VI})$ ion on the adsorption was carried out in the solution $(20 \mathrm{mg} / \mathrm{L}-200 \mathrm{mg} / \mathrm{L})$, at $30^{\circ} \mathrm{C}$ and $\mathrm{pH} 7.0$. The effect of initial $\mathrm{pH}$ value 1 - 9 (adjusted with $0.2 \mathrm{M} \mathrm{HCl}$ or $0.2 \mathrm{M} \mathrm{NaOH}$ ) was conducted in $\mathrm{Cr}(\mathrm{VI})$ ion solution. The bottles were agitated for $120 \mathrm{~min}$. The $\mathrm{Cr}(\mathrm{VI})$ ion concentrations in the filtrate after filtration and the initial concentrations were determined by UV-vis spectrometer. The adsorption capacities were calculated by Equation (1).

$$
q_{e}=\frac{\left(C_{o}-C_{e}\right)}{m} \times V
$$

where $q_{e}$ is the adsorption capacities of hybrid membrane ( $\mathrm{Cr}(\mathrm{VI})$ ion/g adsorbent), $\mathrm{V}$ is the volume of $\mathrm{Cr}(\mathrm{VI})$ ion solution (L), $\mathrm{C} 0$ is the initial concentration of $\mathrm{Cr}(\mathrm{VI})$ ion before adsorption $(\mathrm{mg} / \mathrm{L}), C_{e}$ is the concentration of $\mathrm{Cr}(\mathrm{VI})$ ion after adsorption $(\mathrm{mg} / \mathrm{L})$, that is in filtrate, and $\mathrm{m}$ is the weight of hybrid membrane (g).

\section{Results and Discussion}

\subsection{FT-IR}

The FT-IR spectra of chitosan, CMC and CSMH hybrid membrane are shown in Figure 1. CS presented a 


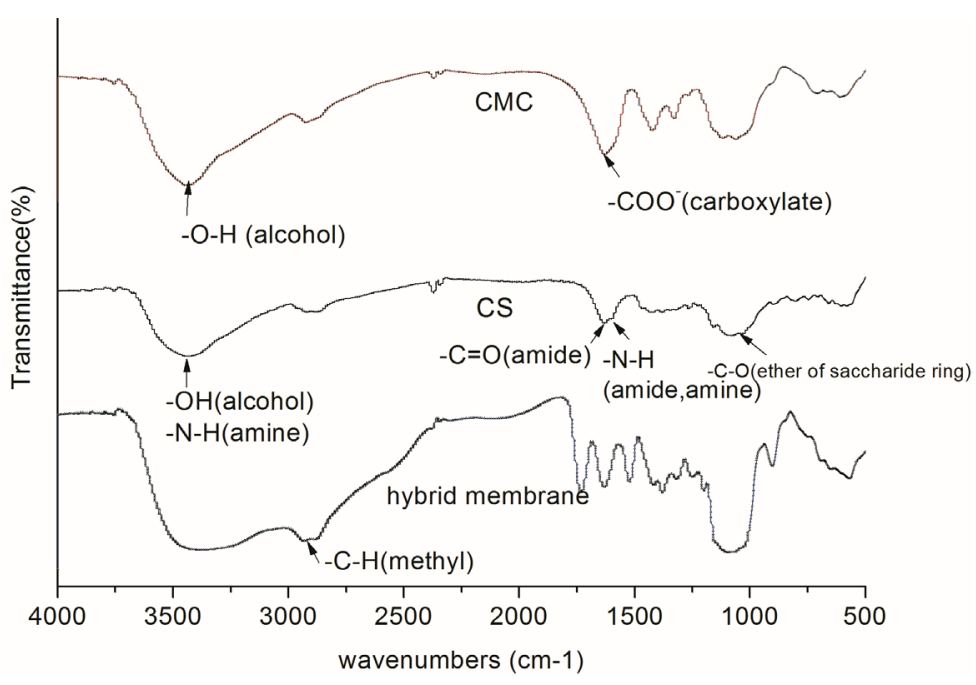

Figure 1. FT-IR spectra of chitosan, CMC and hybrid membrane.

characteristic band at $3450 \mathrm{~cm}^{-1}$ which was attributed to $-\mathrm{NH}_{2}$ and $-\mathrm{OH}$ stretching vibration and $1652 \mathrm{~cm}^{-1}$ which was characteristic of amide group [13]. The FTIR spectrum of CMC showed carboxylate ion -COO- antisymmetric stretching peaks at $1600 \mathrm{~cm}^{-1}$, symmetrical C-O stretching at $1059 \mathrm{~cm}^{-1}$, and C-O-C group at 1630 $\mathrm{cm}^{-1}$ [14]. The FTIR spectrum of hybrid membrane demonstrated a broad band at $3400 \mathrm{~cm}^{-1}$ corresponding to $\mathrm{N}-\mathrm{H}$ stretching (amide II and primary amine of hybrid membrane) and -OH stretching. The bands at around $2933 \mathrm{~cm}^{-1}$ can be assigned to the C-H stretching (methyl group) of hybrid membrane, and $1092 \mathrm{~cm}^{-1}$ and 1200 $\mathrm{cm}^{-1}$ (C-O-C, polysaccharide ring). The hybrid membrane had $1596 \mathrm{~cm}^{-1}(\mathrm{~N}-\mathrm{H})$ and $1740 \mathrm{~cm}^{-1}$ (C=O) which verified that the composite was consist of CS and CMC. The band at $1630 \mathrm{~cm}^{-1}$ became sharper due to the formation of intermolecular interactions between CMC and CS [15]. The peak of asymmetry stretching of COOwas also found at $1420 \mathrm{~cm}^{-1}$. It showed that the strong electrostatic attraction between [ $\mathrm{NH}_{3}^{+}$] of $\mathrm{CS}$ and $\left[\mathrm{COO}^{-}\right]$ of CMC may be the main ion cross-linking interaction leading to the formation of polyelectrolyte network structure. At the same time, -OH has slight band-shifts in composite scaffolds, which means that there are some inter- or intra-hydrogen bonds among these three components of CS/CMC/silica composite membrane. This is agreement with the results from Jang [11]. The vibration frequencies of NH, Si-O-Si, Si-O-H and Si-O were at $1422 \mathrm{~cm}^{-1}, 1092 \mathrm{~cm}^{-1}, 914 \mathrm{~cm}^{-1}$ and $762 \mathrm{~cm}^{-1}$, respectively, which indicated the possible cross-linking between CMC, CS and GPTMS.

\subsection{Morphology of Hybrid Membrane}

The surface morphology of the hybrid membrane was taken using SEM and shown in Figure 2. From Figure 2(a), it can be seen that the pure chitosan membrane has relatively smooth and plain surface. Incorporating silane couple agent into chitosan/carboxymethyl cellulose membrane can affect the surface morphology of the hybrid membrane significantly. As seen from Figure 2(b), uneven membrane surface has been formed, "like island"small protuberant are basically covered on surface of CSMH hybrid membrane and they closely adjacent. The smaller size pores are also observed for CSMH. Because of strong electrostatic interaction between chitosan and sodium carboxymethylcellulose, crosslinking reaction with silane coupling agent occurred at hydroxyl position. Therefore, porous structure in hybrid membrane can be attributed to forming -O- connection between the silicon coupling agent and hydroxyl sites on chitosan and sodium carboxymethyl cellulose [12] [13].

\subsection{Effect of Different Factors on Adsorption Properties of the Hybrid Membrane}

To investigate the effect of the adsorbent quantity on the adsorption capacities, the $160 \mathrm{~g} / \mathrm{mL} \mathrm{Cr}(\mathrm{VI})$ solutions with $\mathrm{pH} 7.0$ were stirred for $2 \mathrm{~h}$ with different amount of CSMH hybrid membrane from 0.1 to $0.5 \mathrm{~g}$. The result is shown in Figure 3(a). The adsorbed quantity of $\mathrm{Cr}(\mathrm{VI})$ per unit mass of the adsorbent increased slowly with the increase of adsorbent up to $0.3 \mathrm{~g}$, and after the critical dose, the adsorption capacities decreased. This increase could be attributed to the increase of the adsorbent surface area and availability of more active 

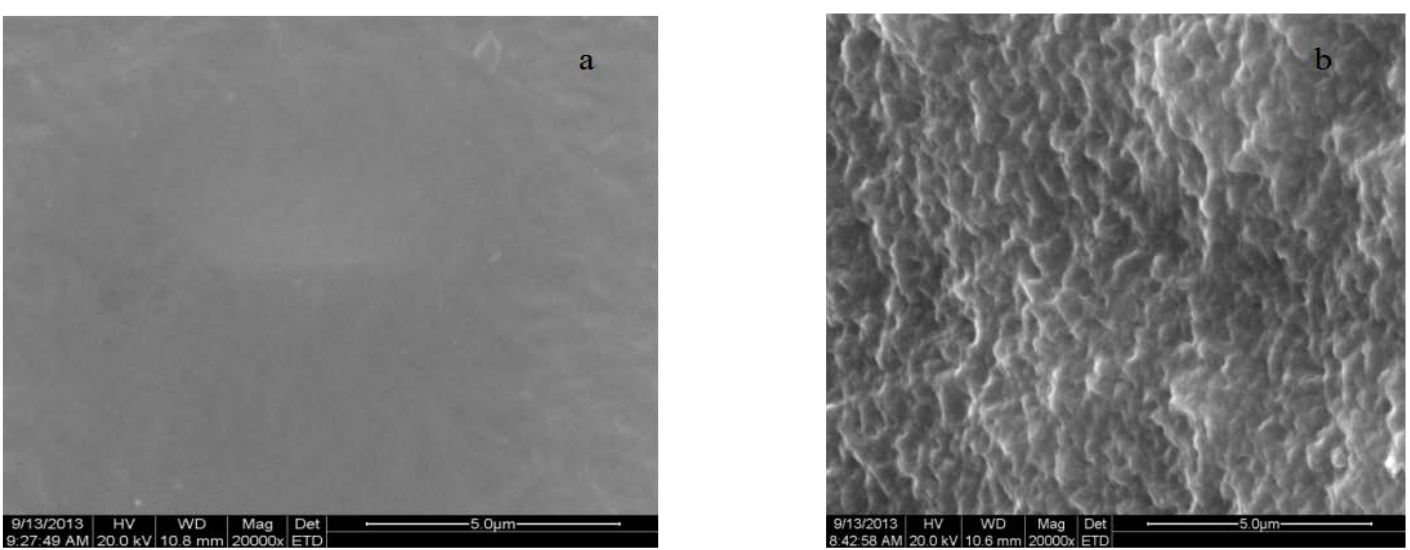

Figure 2. Morphology of pure chitosan and hybrid membrane: (a) Pure chitosan membrane; (b) CSMH.

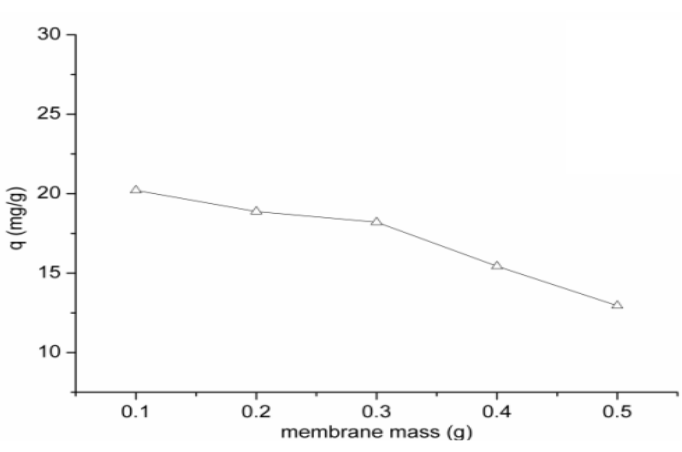

(a)

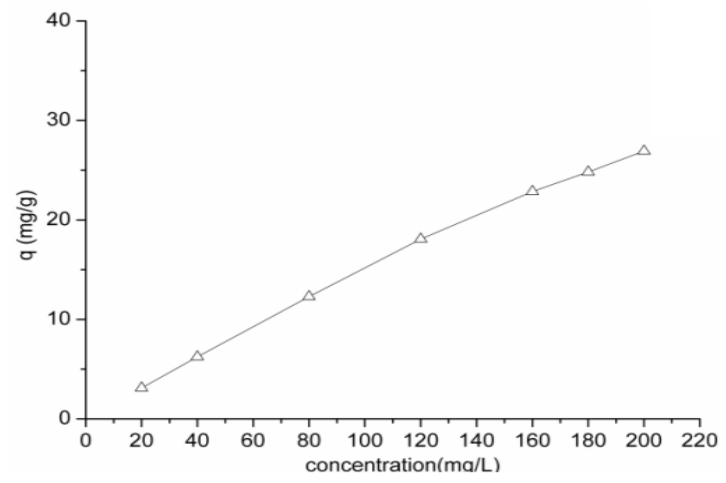

(c)

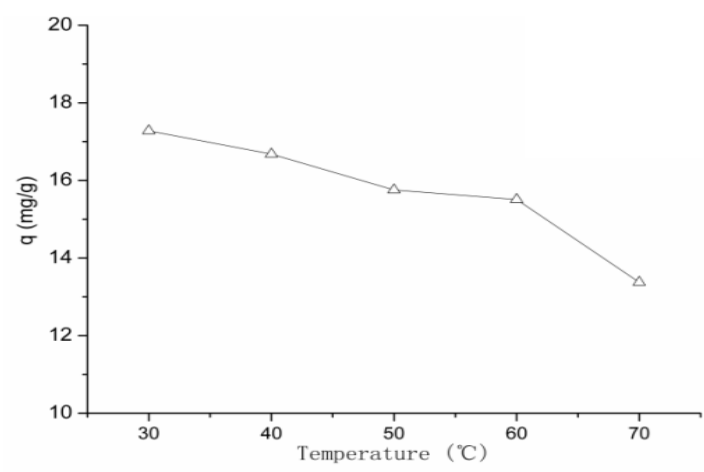

(b)

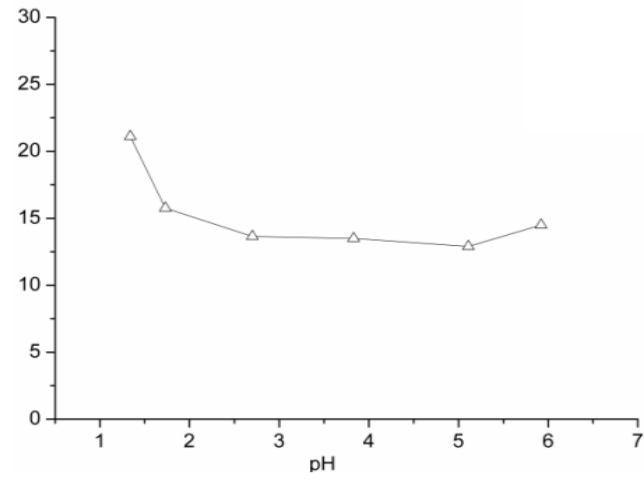

(d)

Figure 3. Effect of different factors on adsorption capacities of CSMH hybrid membrane: (a) Membrane mass; (b) Temperature; (c) Initial concentration; (d) $\mathrm{pH}$.

adsorption sites on the hybrid membrane surface with the increase of it. But when adsorbent dose reached $0.3 \mathrm{~g}$, the adsorption capacity of the hybrid membrane decreased for $\mathrm{Cr}(\mathrm{VI})$. Therefore, the hybrid membranes of $0.3 \mathrm{~g}$ were used for $\mathrm{Cr}(\mathrm{VI})$ in the following experiment. The effect of initial $\mathrm{Cr}(\mathrm{VI})$ concentration on the adsorption efficiency of the hybrid membrane was investigated (shown in Figure 3(b)). With the $\operatorname{Cr}(\mathrm{VI})$ concentration increasing, the adsorption capacity per unit mass of the hybrid membrane increased. The higher initial concentration of $\mathrm{Cr}(\mathrm{VI})$ provided an important driving force to overcome the mass transfer resistance for $\mathrm{Cr}(\mathrm{VI})$ transfer between the solution and the surface of the hybrid membrane. In the process, the $\mathrm{Cr}(\mathrm{VI})$ primarily overcame the boundary layer effect and then diffused from surface to inside of the hybrid membrane.

Temperature is an important controlling factor in the practical applications of the proposed adsorbing process 
since the most of the textile effluents is produced at relatively high temperatures. The results (shown in Figure 3(c)) indicated the adsorption capacity of $\mathrm{Cr}(\mathrm{VI})$ onto the hybrid membrane decreased with an increase in temperature and it indicated that the process was exothermic. The adsorption capacities of $\operatorname{Cr}(\mathrm{VI})$ on the hybrid membrane were examined in different $\mathrm{pH}$ solution at initial dye concentration $120 \mathrm{mg} / \mathrm{L}$, contacting time $2 \mathrm{~h}$ by the batch experiments. The results are shown in Figure 3(c). Cr(VI) adsorption followed a typical metal anion adsorption behavior, where maximum adsorption took place at low $\mathrm{pH}$ between 1 and 2 . With the increase of $\mathrm{pH}$, the adsorption capacities decreased. It was attributed to the deprotonation of the hybrid membrane, which reduced the chelation and absorption of $\mathrm{Cr}(\mathrm{VI})$. High adsorption at acidic $\mathrm{pH}$ conditions could be explained by the chemical character of the chromium species and the adsorbent surface. In the acidic $\mathrm{pH}$ range (1 - 2), the prominent formation of chromium are $\mathrm{Cr}_{2} \mathrm{O}_{7}^{2}-, \mathrm{HCrO}_{4}^{-}$, and above $\mathrm{pH} 7.0$ the primary stable species is $\mathrm{CrO}_{4}^{2-}$. Therefore, at lower $\mathrm{pH}, \mathrm{Cr}_{2} \mathrm{O}_{7}^{2}$ - and $\mathrm{HCrO}_{4}^{-}$were adsorbed onto the hybrid membrane, resulting in a high percentage of adsorption. At basic $\mathrm{pH}$ condition, the suppression of the hydrolysis of $\mathrm{Cr}(\mathrm{VI})$ may be the reason for the decreased adsorption.

\subsection{Adsorption Kinetics}

The adsorption kinetics of $\mathrm{Cr}(\mathrm{VI})$ onto the hybrid membrane was investigated under the condition of the 120 $\mathrm{mg} / \mathrm{L} \mathrm{Cr}(\mathrm{VI})$ at neutral. The samples were taken out at different time intervals in the range of $0-240 \mathrm{~min}$. The results are shown in Figure 4. It can be seen that the adsorption capacity for $\operatorname{Cr}(\mathrm{VI})$ increased with the increase of contacting time. The $\mathrm{Cr}(\mathrm{VI})$ reached equilibrium at $60 \mathrm{~min}$, The $\mathrm{Cr}(\mathrm{VI})$ uptake potential indicate that most of the active sites of the hybrid membrane were exposed for interaction with the $\operatorname{Cr}(\mathrm{VI})$ ion. In order to investigate the mechanism of the adsorption process, the pseudo-first-order equation, the pseudo-second-order equation and particle diffusion equation based on adsorption equilibrium capacity can be expressed by Equations (2)-(4) [14] [15] respectively.

$$
\begin{gathered}
\ln \left(q_{e}-q_{t}\right)=\ln q_{e}-\frac{k_{1} t}{2.303} \\
\frac{t}{q_{t}}=\frac{1}{k_{2} q_{e}^{2}}+\frac{t}{q_{e}} \\
q_{t}=k_{i} t^{1 / 2}+C
\end{gathered}
$$

where $q_{e}(\mathrm{mg} / \mathrm{g})$ and $q_{t}(\mathrm{mg} / \mathrm{g})$ are the adsorption quantity at adsorption equilibrium and the adsorption quantity at time $t(\mathrm{~min})$, respectively, $k_{1}\left(\mathrm{~min}^{-1}\right)$ and $k_{2}\left(\mathrm{~min} \cdot \mathrm{g} \cdot \mathrm{mg}^{-1}\right)$ are the kinetic rate constants for the pseudo-firstorder equation and the pseudo-second-order equation, respectively. The slopes and intercepts of plots of $1-\ln$ $\left[\left(\mathrm{q}_{\mathrm{e}}-\mathrm{q}_{\mathrm{t}}\right) / \mathrm{q}_{\mathrm{e}}\right]$ versus $\mathrm{t}$ are used to determine the pseudo-first-order rate constant $k_{1}$ and $\mathrm{q}_{\mathrm{e}}$. The slopes and intercepts of plots of $t / q_{t}$ versus $t$ are used to calculate the pseudo-second-order rate constant $k_{2}$ and $\mathrm{q}_{\mathrm{e}}$. $\mathrm{k}_{\mathrm{i}}$ and $\mathrm{C}$ are respectively rate constant and constant for the particle diffusion equation [16] [17]. The results are shown in Figure 4(b). The calculated results are summarized in Table 1. It is found that the adsorption behavior of free

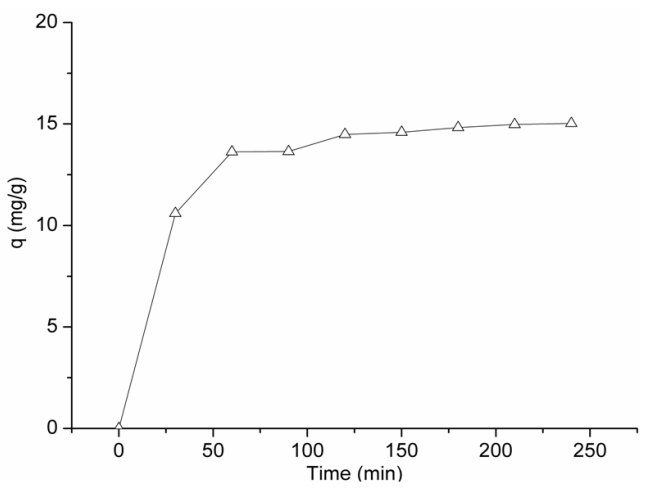

(a)

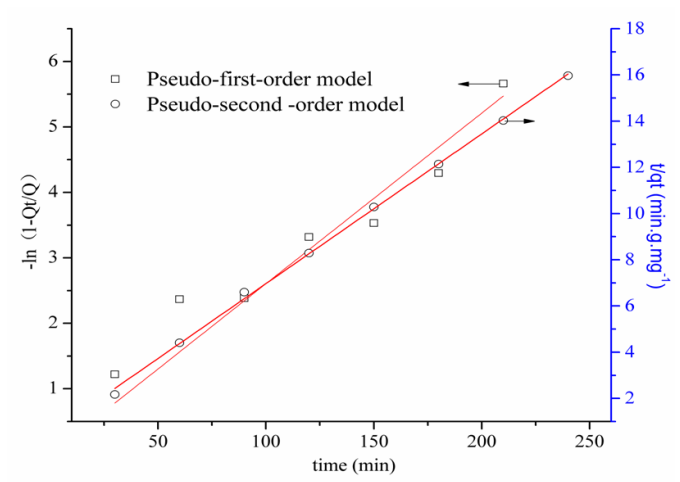

(b)

Figure 4. (a) Adsorption kinetics curves of hybrid membrane; (b) Test of pseudo first-order and secondorder equation for $\mathrm{Cr}(\mathrm{VI})$. 
Table 1. Comparison of the pseudo-first and pseudo-second order constant.

\begin{tabular}{ccccccc}
\hline \multirow{2}{*}{ Metal ion } & \multicolumn{2}{c}{ Pseudo-first-order model } & \multicolumn{4}{c}{ Pseudo-second-order model } \\
\cline { 2 - 7 } & $\mathrm{K}_{1}\left(\mathrm{~min}^{-1}\right)$ & $\mathrm{R}^{2}$ & $\mathrm{~K}_{2}\left(* 10^{-3} \mathrm{~g} \cdot \mathrm{mg}^{-1} \cdot \mathrm{min}\right)$ & $\mathrm{R}^{2}$ & $\mathrm{Q} /(\mathrm{mg} / \mathrm{g})$ & $\mathrm{t}_{1 / 2}(\mathrm{~min})$ \\
\hline $\mathrm{Cr}(\mathrm{VI})$ & 0.0260 & 0.9171 & 3.880 & 0.9908 & 16.08 & 16.03 \\
\hline
\end{tabular}

a (at $30^{\circ} \mathrm{C}, \mathrm{C}_{0}=120 \mathrm{mg} / \mathrm{L}, \mathrm{pH}$ neutral).

$\mathrm{Cr}(\mathrm{VI})$ ions could be best described by the pseudo-second-order model. This result indicates that chemisorption mechanism might play an important role for the adsorption of $\mathrm{Cr}(\mathrm{VI})$ ions onto the hybrid membrane.

\section{Conclusion}

By using glycidoxypropyltrimethoxysilane (GPTMS) as crosslinking agents, chitosan/carboxy methylcellulose/silica hybrid membrane was prepared. The hybrid membranes contained $\mathrm{COOH}, \mathrm{NH}_{3}{ }^{+}$and -O- functional groups. The hybrid membrane could be employed as an adsorbent for $\mathrm{Cr}(\mathrm{VI})$ removal from waste effluents in acid medium. Adsorption equilibrium of hybrid membrane on $\operatorname{Cr}(\mathrm{VI})$ ion was reached in $60 \mathrm{~min}$. The kinetic data conformed better to the pseudo-second order equation. Chemisorption mechanism might play an important role for the adsorption of $\mathrm{Cr}(\mathrm{VI})$ ions onto the hybrid membrane.

\section{Acknowledgements}

The project was supported by the agricultural science and technology innovation projects of Yancheng (No.YKN2014014).

\section{References}

[1] Crini, G. and Badot, P.-M. (2008) Application of Chitosan, a Natural Aminopolysaccharide, for Dye Removal from Aqueous Solutions by Adsorption Processes Using Batch Studies: A Review of Recent Literature. Prog Polym Sci, 33, 399-447. http://dx.doi.org/10.1016/j.progpolymsci.2007.11.001

[2] Kyzas, G.Z., Kostoglou M. and Lazaridis, N.K. (2009) Copper and Chromium(VI) Removal by Chitosan DerivativesEquilibrium and Kinetic Studies. Chem Eng J, 152, 440-448. http://dx.doi.org/10.1016/j.cej.2009.05.005

[3] Shimizu, Y., Tanigawa, S., Saito, Y. and Nakamura, T. (2005) Synthesis of Chemically Modified Chitosans with a Higher Fatty Acid Glycidyl and Their Adsorption Abilities for Anionic and Cationic Dyes. Journal of Applied Polymer Science, 96, 2423-2428. http://dx.doi.org/10.1002/app.21707

[4] Grisdanurak, N., Akewaranugulsiri, S., Futalan, C.M., Tsai, W.-C., Kan, C.-C., Hsu, C.-W. and Wan, M.-W. (2012) The Study of Copper Adsorption from Aqueous Solution Using Crosslinked Chitosan Immobilized on Bentonite. Journal of Applied Polymer Science, 125, E132-E142. http://dx.doi.org/10.1002/app.35541

[5] Salehi, E., Madaeni, S.S., Rajabi, L., Derakhshan, A.A., Daraei, S. and Vatanpour, V. (2013) Static and Dynamic Adsorption of Copper Ions on Chitosan/Polyvinyl Alcohol Thin Adsorptive Membranes: Combined Effect of Polyethylene Glycol and Aminated Multi-Walled Carbon Nanotubes. Chemical Engineering Journal, 215-216, 791-801. http://dx.doi.org/10.1016/j.cej.2012.11.071

[6] Zha, F., Li, S., Chang, Y. and Yan, J. (2008) Preparation and Adsorption Kinetics of Porous $\gamma$-Glycidoxypropyltrimethoxysilane Crosslinked Chitosan- $\beta$-Cyclodextrin Membranes. Journal of Membrane Science, 321, 316-323. http://dx.doi.org/10.1016/j.memsci.2008.05.007

[7] Han, B., Zhang, D., Shao, Z., Kong, L. and Lv, S. (2013) Preparation and Characterization of Cellulose Acetate/Carboxymethyl Cellulose Acetate Blend Ultrafiltration Membranes. Desalination, 311, 80-89. http://dx.doi.org/10.1016/j.desal.2012.11.002

[8] Boricha, A.G. and Murthy, Z.V.P. (2010) Preparation of N,O-Carboxymethyl Chitosan/Cellulose Acetate Blend Nanofiltration Membrane and Testing Its Performance in Treating Industrial Wastewater. Chemical Engineering Journal, 157, 393-400. http://dx.doi.org/10.1016/j.cej.2009.11.025

[9] Mondal, D., Bhowmick, B., Mollick, M.M., Maity, D., Mukhopadhyay, A., Rana, D. and Chattopadhyay, D.(2013) Effect of Clay Concentration on Morphology and Properties of Hydroxypropylmethylcellulose Films. Carbohydrate Polymers, 96, 57-63. http://dx.doi.org/10.1016/j.carbpol.2013.03.064

[10] Baysal, K., Aroguz, A.Z., Adiguzel, Z. and Baysal, B.M. (2013) Chitosan/Alginate Crosslinked Hydrogels: Preparation, Characterization and Application for Cell Growth Purposes. International Journal of Biological Macromolecules, 59, 
342-348. http://dx.doi.org/10.1016/j.ijbiomac.2013.04.073

[11] Jiang, L., Li, Y., Wang, X., Zhang, L., Wen, J. and Gong, M. (2008) Preparation and Properties of Nano-Hydroxyapatite/Chitosan/Carboxymethyl Cellulose Composite Scaffold. Carbohydrate Polymers, 74, 680-684. http://dx.doi.org/10.1016/j.carbpol.2008.04.035

[12] Soares, K.V., Masini, J.C., Torresi, R.M., Carmona-Ribeiro, A.M. and Petri, D.F.S. (2005) Hybrid Particles of Polystyrene and Carboxymethyl Cellulose as Substrates for Copper Ions. Langmuir, 21, 8515-8519. http://dx.doi.org/10.1021/la050493r

[13] Liu, C. and Bai, R. (2006) Adsorptive Removal of Copper Ions with Highly Porous Chitosan/Cellulose Acetate Blend Hollow Fiber Membranes. Journal of Membrane Science, 284, 313-322. http://dx.doi.org/10.1016/j.memsci.2006.07.045

[14] Hsiao, M.-H., Tung, T.-H., Hsiao, C.-S. and Liu, D.-M. (2012) Nano-Hybrid Carboxymethyl-Hexanoyl Chitosan Modified with (3-Aminopropyl)Triethoxysilane for Camptothecin Delivery. Carbohydrate Polymers, 89, 632-639. http://dx.doi.org/10.1016/j.carbpol.2012.03.066

[15] Faria, E.A. and Prado, A.G.S. (2007) Kinetic Studies of the Thermal Degradation of Cellulose Acetate/Niobium and Chitosan/Niobium Composites. Reactive and Functional Polymers, 67, 655-661. http://dx.doi.org/10.1016/j.reactfunctpolym.2007.04.003

[16] Bernardo, G.R., Rene, R.M. and Ma Catalina, A.D. (2009) Chromium(III) Uptake by Agro-Waste Biosorbents: Chemical Characterization, Sorption-Desorption Studies, and Mechanism. Journal of Hazardous Materials, 170, 845-854. http://dx.doi.org/10.1016/j.jhazmat.2009.05.046

[17] Boddu, V.M., Abburi, K., Talbott, J.L. and Smith, E.D. (2003) Removal of Hexavalent Chromium from Wastewater Using a New Composite Chitosan Biosorbent. Environmental Science \& Technology, 37, 4449-4456. http://dx.doi.org/10.1021/es021013a 